\title{
Cumprimento dos requisitos da certificação FSC/CoC por indústrias moveleiras do Rio de Janeiro
}

\author{
Compliance of FSC/CoC certification requirements for Rio de Janeiro wooden \\ mobile industries
}

\section{Natália Dias de Souza ${ }^{\mathrm{I}}$, Talles de Assis Leão ${ }^{\mathrm{II}}$, Ananias Francisco Dias Júnior ${ }^{\mathrm{III}}$, Alexandre Monteiro de CarvalhoI, Eduardo Vinicius da Silva ${ }^{\mathrm{I}}$}

\begin{abstract}
Resumo
O objetivo desse estudo foi analisar a capacidade das indústrias moveleiras da região metropolitana do Rio de Janeiro, em atender aos requisitos das certificações de cadeia de custódia do Forest Council Stewardship (FSC). Os dados foram coletados através da aplicação de questionários contendo informações sobre a certificação florestal (administração participativa, capacitação dos funcionários, documentação legal da empresa, fornecedores certificados, rastreabilidade da matéria-prima e relatório de movimentação de certificação). Os questionários foram preenchidos durante visitas às empresas, respondidos pelo responsável do setor de projeto e produção. Os requisitos "disposição de licenças e outros documentos legais", "disponibilidade de um responsável pelo processo de certificação de cadeia de custódia” e "capacitação de funcionários", que necessitam de custos e que exigem procedimentos burocráticos para cumprimento, foram os que mais interferiram para que as empresas não obtivessem o certificado de cadeia de custódia. O requisito-chave "rastreabilidade da matéria-prima" não apresentou complexidade de cumprimento, visto que todas as indústrias afirmaram ter capacidade em atendê-lo. Em relação à norma de certificação de cadeia de custódia, a maioria das indústrias moveleiras da região metropolitana do Rio de Janeiro consegue cumprir os requisitos exigidos.
\end{abstract}

Palavras-chave: Requisitos FSC; Certificação florestal; Gestão pela qualidade

\begin{abstract}
This research aimed to analyze the ability of the Rio de Janeiro metropolitan furniture industries to meet the requirements of Forest Council Stewardship chain of custody certifications (FSC). Data were collected through the application of questionnaires containing information on forest certification (participatory management, employee training, company legal documentation, certified suppliers, raw material traceability and certification movement report). The questionnaires were completed during visits to the companies, answered by the head of the design and production sector. The requirements "provision of licenses" and "other legal documents", "availability of chain of custody certification process officer" and "staff training", which require costs and require bureaucratic compliance procedures, were the ones that influenced the companies not to obtain the chain of custody certificate. The key requirement "raw material traceability" did not present compliance complexity, as all industries claimed to be able to meet it. In the chain of custody certification standard, most furniture industries in the Rio de Janeiro metropolitan region can meet the required requirements.
\end{abstract}

Keywords: FSC requirements; Forest certification; Quality by management

Engenheiro Florestal, Dr., Professor do Instituto de Florestas, Universidade Federal Rural do Rio de Janeiro, BR 465 km 07, Campus Universitário, CEP 23897-000, Seropédica (RJ), Brasil. natdias@hotmail.com (ORCID: 0000-0002-9322-9669) / amcarvalho@ufrrj.br (ORCID: 0000-0002-4924-5362) / eduvini@gmail.com (ORCID: 0000-0003-0339-4319)

II Engenheiro Florestal, Analista da Fundação Parques e Jardins, Rua Afonso Cavalcanti, 455, Cidade Nova, CEP 20211-110, Rio de Janeiro (RJ), Brasil. tallesleao@oi.com.br (ORCID: 0000-0002-2148-4433)

III Engenheiro Florestal, Dr., Professor do Departamento de Ciências Florestais e da Madeira, Universidade Federal do Espírito Santo, Av. Governador Lindemberg, 316, Centro, CEP 29550-000, Jerônimo Monteiro (ES), Brasil. ananias.dias@ufes.br (ORCID: 0000-0001-9974-0567) 


\section{Introdução}

A certificação é o conjunto de atividades desenvolvidas por um organismo independentemente da relação comercial, com o objetivo de atestar publicamente que determinado produto, processo ou serviço está em conformidade com certos requisitos (ALVES, 2010). As atividades de certificação envolvem análise de documentação, auditorias e inspeções na empresa, coleta e ensaios de produtos, no mercado ou na fábrica, com objetivo de avaliar a conformidade e sua manutenção (JÚNIOR et al., 2008). A adesão é voluntária por parte das empresas (SOARES, 2013). A certificação pode ser implementada em qualquer tipo de empresa ou instituição, independentemente do seu tipo, do seu porte e do produto que fornece (LUZ e LIGUORI, 2012). As empresas aderem à certificação, principalmente pelas exigências do mercado, pela opção de utilizar o selo em seus produtos, pela abertura de novos mercados, pela melhoria dos sistemas de gestão e desempenho e pela melhora na comunicação com fornecedores (ARAUJO et al., 2009; JACOVINE et al., 2006a). As certificações florestais, como as do Forest Council Stewardship (FSC) e o Programa Brasileiro de Certificação Florestal (CERFLOR), associado ao Programme for the Endorsement of Forest Certification (PEFC), visam certificar produtos de origem de florestas manejadas de maneira ambientalmente adequadas, socialmente justas e economicamente viáveis (PINTO e PRADA, 2008).

O FSC é o sistema mais estudado por ser o sistema pioneiro e de maior credibilidade em inspeção de certificação florestal (MARCOVITCH, 2012). É ainda, uma organização internacional não governamental, independente, formada por ambientalistas, pesquisadores, representantes de movimentos sociais, produtores rurais, empresários e representantes de populações tradicionais (DA LUZ, 2010). O FSC tem três tipos de certificados: Manejo Florestal (FM), Cadeia de Custódia (CoC) e madeira Controlada (CW) (FSC, 2019). Dentre esses, o certificado de cadeia de custódia $(\mathrm{CoC})$ é o que se aplica às indústrias moveleiras, ou seja, emprega-se aos produtores que processam a matéria-prima de florestas certificadas (ALVES et al., 2009a; ALVES; JACOVINE; EINLOFT, 2009b). Segundo FSC (2019) existem atualmente no mundo 39.534 certificados em cadeia de custódia, sendo 1.012 destes no Brasil. A indústria moveleira é um segmento produtivo que tem adquirido o certificado florestal nos últimos anos, mesmo que de forma bastante incipiente, em um número de aproximadamente 150 certificados (GUSMÃO et al., 2014).

Para incrementar a participação do setor moveleiro na certificação florestal é necessário conscientizar os componentes envolvidos, explicando as vantagens que o certificado pode proporcionar as organizações. As certificadoras e as empresas certificadas devem divulgar a certificação florestal de forma positiva e real, como por exemplo: os custos são acessíveis para as empresas moveleiras; é um processo viável, visto que muitas empresas moveleiras já adquirem matéria-prima certificada (painéis); a implantação da certificação é independente, a empresa não necessita possuir outro tipo de certificado; propicia uma excelente oportunidade de valorização e diferenciação dos produtos no mercado; permite a consolidação de práticas para o desenvolvimento sustentável; constitui um importante fator de incremento de vendas e melhoria da imagem da empresa; é um mecanismo importante na visão gerencial e estratégica das empresas no que se refere ao aumento da competitividade e ganho de mercado; aumenta a satisfação dos clientes internos e externos; representa um fator de competitividade para a exportação (JACOVINE et al., 2006b; ALVES; JACOVINE; EINLOFT, 2009a; PINTO e GRANJA, 2013). Este trabalho de pesquisa teve por objetivo analisar a capacidade das indústrias moveleiras da região metropolitana do Rio de Janeiro em atender aos requisitos da certificação de cadeia de custódia (FSC/CoC).

\section{Material e métodos}

O estudo foi realizado em empresas moveleiras localizadas na região metropolitana do Rio de Janeiro - RJ, Brasil. Para selecionar as indústrias foi efetuada uma pesquisa nos sindicatos 
da região: SIM-Rio (Sindicato das Indústrias de Móveis de Madeira do Município do Rio de Janeiro) e SINCOCIMO (Sindicato das Indústrias de Construção Civil e do Mobiliário da Baixada Fluminense). Foram selecionados os estabelecimentos que apresentaram um parque fabril, ou seja, endereço fixo, equipamentos instalados e em atividade produtiva industrial.

\section{Coleta e análise dos dados}

Para a coleta dos dados desta pesquisa, foi utilizado um questionário confeccionado segundo critérios preestabelecidos por especialistas na área. O questionário apresentava perguntas abertas (os respondentes ficam livres para responder com suas próprias palavras), fechadas (os respondentes devem optar por uma das alternativas apresentadas no questionário) e dicotômicas (os respondentes devem optar entre duas opções).

Neste trabalho, considerou-se como atendimento da norma para certificação de cadeia de custódia o cumprimento de todos os requisitos-chave, sendo eles: fornecedores de matériaprima certificados; disposição de licenças e outros documentos legais; comprometimento e responsabilidade da alta direção em divulgar e a cumprir a política da cadeia de custódia; disponibilidade de um responsável pelo processo de certificação de cadeia de custódia; rastreabilidade da matéria-prima; capacitação de seus funcionários e sistema de controle documentado. Para verificar a capacidade das empresas em atender aos padrões exigidos pela norma do certificado de cadeia de custódia do FSC, avaliaram-se as perguntas do questionário relacionadas aos requisitos-chave, que são: pergunta 3 (P3) requisito: fornecedores certificados; pergunta 5 (P5) requisito: disposição de licenças e outros documentos legais; pergunta 6 (P6) requisito: comprometimento e responsabilidade da alta direção em divulgar e a cumprir a política da cadeia de custódia; pergunta 7 (P7) requisito: disponibilidade de um responsável pelo processo de certificação de cadeia de custódia; pergunta 8 (P8) requisito: rastreabilidade da matéria-prima; pergunta 9 (P9) requisito: capacitação de seus funcionários; pergunta 11 (P11) requisito: sistema de controle documentado.

\section{Análise dos dados}

Os dados foram analisados com o auxílio da estatística descritiva, organizados e sistematizados por meio de tabulação. O agrupamento dos requisitos exigidos para a certificação de cadeia de custódia foi realizado utilizando a técnica de análise de componentes principais, sendo analisada a ocorrência de possíveis correlações, baseadas nos valores das variáveis (requisitos da certificação) e nos vetores gerados, em matrizes simétricas. Dessa forma, a análise foi conduzida com o intuito de explicar a estrutura de variância composta pelas perguntas selecionadas do questionário. Para isso, foi utilizada a lógica binária para cada pergunta formulada (MINGOTI, 2013). Assim, cada pergunta elaborada foi passível de dois valores: 1 (para respostas com aspectos positivos à certificação) e 2 (para aspectos negativos à certificação). Foram consideradas as médias padronizadas (valor 0 ) e desvio padrão igual a 1, para cada empresa estudada. Para a análise das componentes principais (ACP) utilizou-se a matriz de correlação dos dados. As combinações lineares estabelecidas foram interpretadas por meio dos autovetores normalizados e das correlações entre as variáveis originais e as componentes principais estabelecidas.

\section{Resultados e Discussão}

Dos trinta estabelecimentos avaliados, apenas nove continham parque fabril. Dentre essas empresas, cinco responderam o questionário. Nenhuma empresa apresentou o certificado 
de cadeia de custódia (Figura 1). Menos de 1\% das indústrias do setor moveleiro nacional possui o selo FSC/CoC (GUSMÃO et al., 2014). Todavia, foi detectado o interesse dos empresários moveleiros da região em se certificar, já que $40 \%$ das empresas pesquisadas encontram-se em processo de certificação (Figura 1).

Figura 1 - Empresas moveleiras da região metropolitana do Rio de Janeiro em relação à certificação florestal (FSC/CoC)

Figure 1 - Furniture companies from the metropolitan area of Rio de Janeiro in relation to forest certification $(\mathrm{FSC} / \mathrm{CoC})$

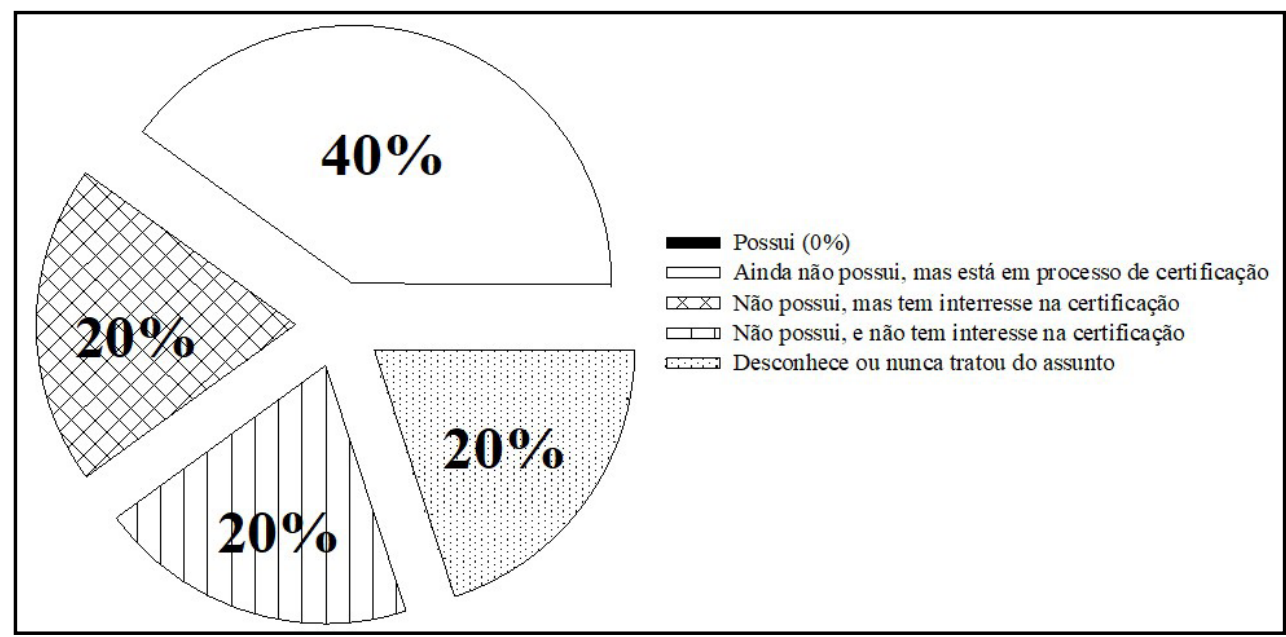

Fonte: Autores (2016)

As empresas em processo de certificação fazem parte de um convênio estabelecido pelo Serviço Brasileiro de Apoio às Micro e Pequenas Empresas (SEBRAE) e o comitê organizador dos jogos olímpicos Rio 2016. Dentro desse convênio foi desenvolvido o "Programa SEBRAE no Pódio", que tem como objetivo auxiliar as empresas moveleiras a obter o certificado florestal. Além do subsídio financeiro, o SEBRAE disponibiliza consultoria para adequação da empresa aos requisitos da certificação. A aquisição do certificado permitirá às empresas moveleiras a participarem das oportunidades de negócios que serão geradas por ocasião desse evento esportivo, visto que para compartilharem das concorrências oferecidas pelos jogos, a empresa obrigatoriamente precisa ter o selo FSC. Essa exigência faz parte de um acordo entre o FSC e o comitê organizador dos jogos olímpicos Rio 2016 (FSC BRASIL, 2013).

Apesar do incentivo, algumas empresas ainda desconheciam o termo ou não apresentavam interesse na certificação propriamente dita (Figura 1). Neste contexto, pode-se afirmar que há um desconhecimento por parte da maioria das empresas moveleiras brasileiras do que seja a certificação florestal, mesmo entre as exportadoras (ALVES etal., 2009a). Paraverificar a capacidade das empresas moveleiras da região metropolitana do Rio de Janeiro em atender aos padrões exigidos pela norma efetuou-se a avaliação através da análise de componentes principais (ACP) relacionada aos requisitos-chave para certificação de cadeia de custódia. O resultado exposto na Figura 2 indica que as duas primeiras componentes principais explicam aproximadamente $94,5 \%$ da variância total dos dados avaliados (os dados mais relevantes amostrados estão contidos nestas duas componentes). A partir da terceira componente, os valores da variância não apresentaram alterações significativas. 


\section{Figura 2 - Variância explicada acumulada e autovalores obtidos da matriz de correlação}

Figure 2 - Explained variance accumulated and eigenvalues obtained from the correlation matrix

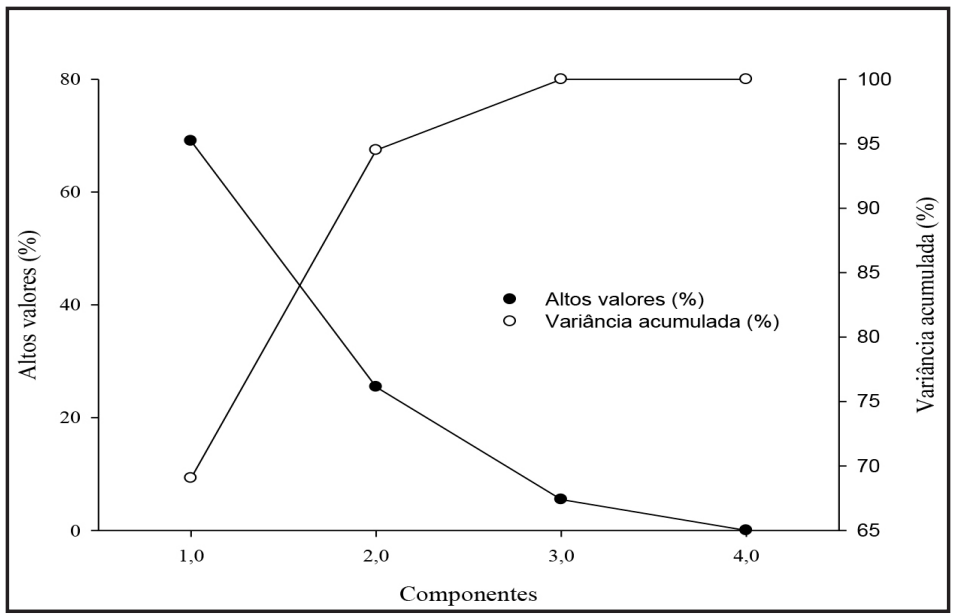

Fonte: Autores (2016)

Ao analisar os valores da Tabela 1, observa-se na componente I os maiores autovetores para a pergunta 3 (fornecedores certificados), pergunta 6 (comprometimento e responsabilidade da alta direção em divulgar e a cumprir a política da cadeia de custódia) e pergunta 11 (sistema de controle documentado), indicando que essas foram as variáveis mais relevantes para separar as empresas no sentido de aquisição do certificado.

\section{Tabela 1 - Autovetores das duas primeiras componentes principais}

Table 1 - Eigenvectors of the first two principal components

\begin{tabular}{|c|c|c|}
\hline Pergunta & Componente I & Componente II \\
\hline P3 & 0,472 & 0,180 \\
\hline P5 & 0,142 & 0,703 \\
\hline P6 & 0,472 & 0,180 \\
\hline P7 & 0,393 & $-0,451$ \\
\hline P9 & 0,393 & $-0,451$ \\
\hline P11 & 0,472 & 0,180 \\
\hline Variância explicada (\%) & 69,06 & 25,44 \\
\hline Variância acumulada (\%) & 69,06 & 94,50 \\
\hline Autovalores & 4,14 & 1,52 \\
\hline
\end{tabular}

Fonte: Autores (2016)

Já na componente principal II, os maiores valores dos autovetores foram observados para a pergunta 5 (disposição de licenças e outros documentos legais), pergunta 7 (disponibilidade de um responsável pelo processo de certificação de cadeia de custódia) e pergunta 9 (capacitação de seus funcionários), indicando que as mesmas apresentam potencial para agrupar as empresas em relação à obtenção da certificação. Analisando o diagrama de ordenação (Figura 3), pode-se 
verificar como as empresas estão agrupadas em relação à certificação florestal. Com relação à componente I, a pergunta 3 (fornecedores certificados), pergunta 6 (comprometimento e responsabilidade da alta direção em divulgar e a cumprir a política da cadeia de custódia) e pergunta 11 (sistema de controle documentado) separaram a empresa C das demais.

Figura 3 - Diagrama de ordenação das empresas moveleiras considerando os escores e autovetores das componentes principais I e II

Figure 3 - Ordination diagram of furniture companies investigated considering the scores and eigenvectors of the main components I and II

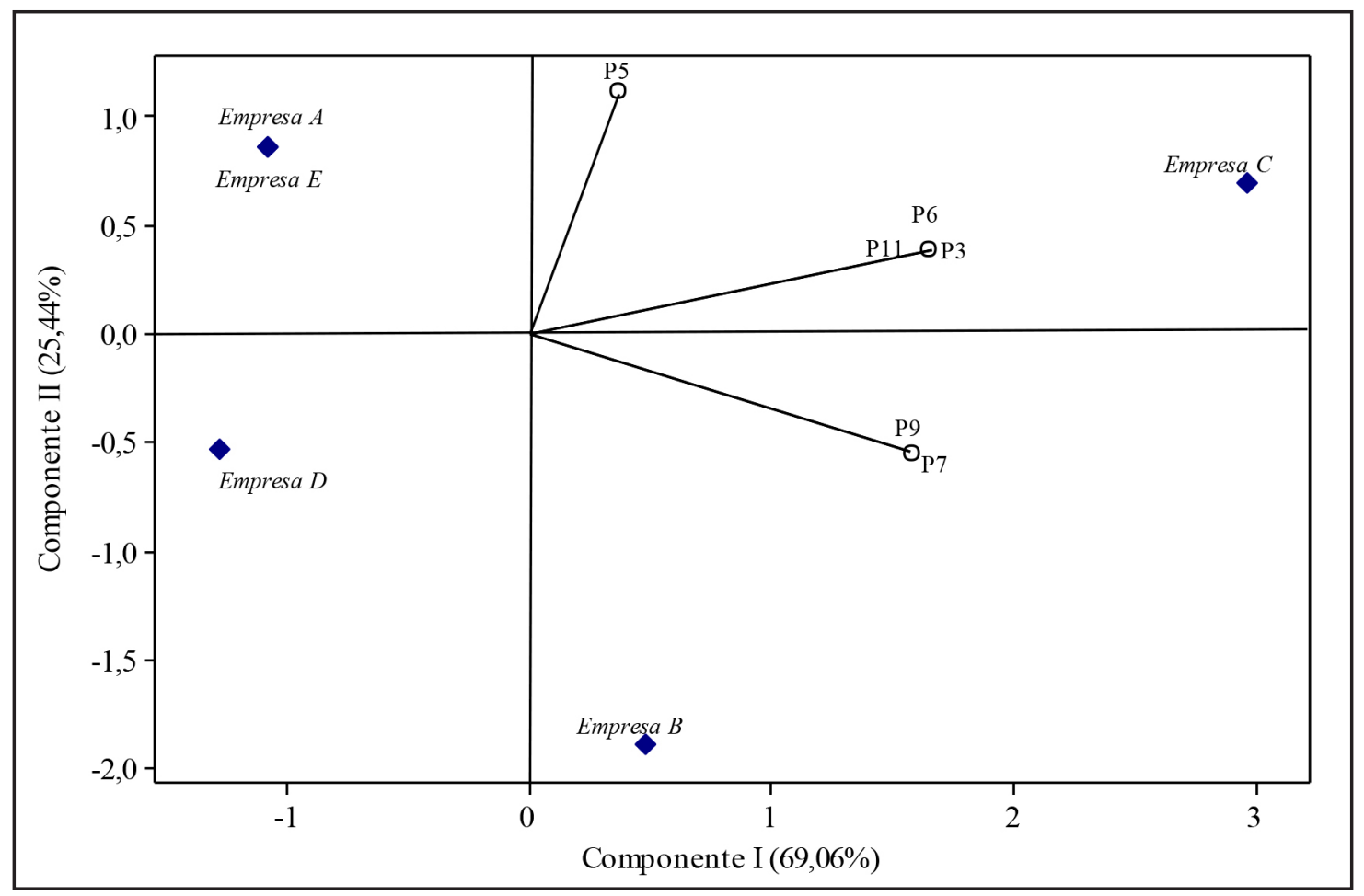

Fonte: Autores (2016)

No lado positivo da componente II, a pergunta 5 foi a que mais se aproximou das empresas A e E. Já no lado negativo dessa mesma componente, a pergunta 7 e a pergunta 9 separaram a empresa B. De forma isolada, nenhuma das perguntas permitiu o agrupamento da empresa D às demais empresas como pode ser observado na ordenação. É possível afirmar, com base nos resultados da Tabela 1 e Figura 3, que as empresas moveleiras da região metropolitana do Rio de Janeiro encontram-se divididas em quatro grupos: I) grupo formado pela empresa C (empresa que não atende à maioria dos requisitos-chave para certificação de cadeia de custódia); II) grupo contendo as empresas $\mathrm{A}$ e $\mathrm{E}$ (empresas que conseguem cumprir a maioria dos requisitos, não atendendo apenas ao requisito de disposição de licenças e outros documentos legais (pergunta 5); III) grupo contendo a empresa $D$ (empresa que cumpre a todos os requisitos exigidos para certificação de cadeia de custódia); e, IV) grupo formado pela empresa B (empresa que não atende aos requisitos de disponibilidade de um responsável pelo processo de certificação de cadeia de custódia e capacitação de seus funcionários (perguntas 7 e 9)). Os requisitos relacionados às perguntas 5, 7 e 9 (disposição de licenças e outros documentos legais; disponibilidade de um responsável pelo processo de certificação de cadeia de custódia e capacitação de seus funcionários, respectivamente) impediram a maioria das empresas moveleiras da região metropolitana do Rio de Janeiro de estar apta para obtenção do certificado de cadeia de custódia. Ressalta-se que 
os referidos requisitos demandam custos para serem implementados exigindo procedimentos burocráticos para serem atendidos.

A dificuldade para a certificação florestal no Brasil está na certificação de pequenas e médias empresas. Para este grupo de produtores, a adequação ao padrão da certificação tem várias barreiras, incluindo a questão dos custos e a dificuldade na adequação às leis ambientais e trabalhistas (SOARES et al., 2011). O requisito-chave "rastreabilidade da matéria-prima" (pergunta 8) foi considerado o de maior facilidade de cumprimento pelas empresas moveleiras da região metropolitana do Rio de Janeiro, visto que, todas as empresas afirmaram ter capacidade em atender a essa exigência, e por isso, foi retirado da análise de componentes principais. Esse resultado é positivo para a aquisição do certificado florestal, em que o principal objetivo da cadeia de custódia é assegurar que produtos florestais certificados não sejam misturados com produtos não certificados (FARIA, 2009).

A maioria das empresas da região metropolitana do Rio de Janeiro $(80 \%)$ considerou a falta de conhecimento sobre a certificação florestal por parte das indústrias moveleiras, o fator limitante para o baixo número de empresas do setor com certificado de cadeia de custódia (FSC/ $\mathrm{CoC}$ ) (Figura 4). Os mesmos relataram que não despertaram para implantação da certificação florestal, principalmente, pela não exigência do mercado, pela falta de visão gerencial, ou mesmo desconhecimento da certificação (ALVES; JACOVINE; EINLOFT, 2009 a).

\section{Figura 4 - Razões apontadas para o pequeno número de empresas do setor moveleiro com certificado de cadeia de custódia (FSC/CoC)}

Figure 4 - Reasons cited for the small number of chain of custody certified furniture companies (FSC/CoC)

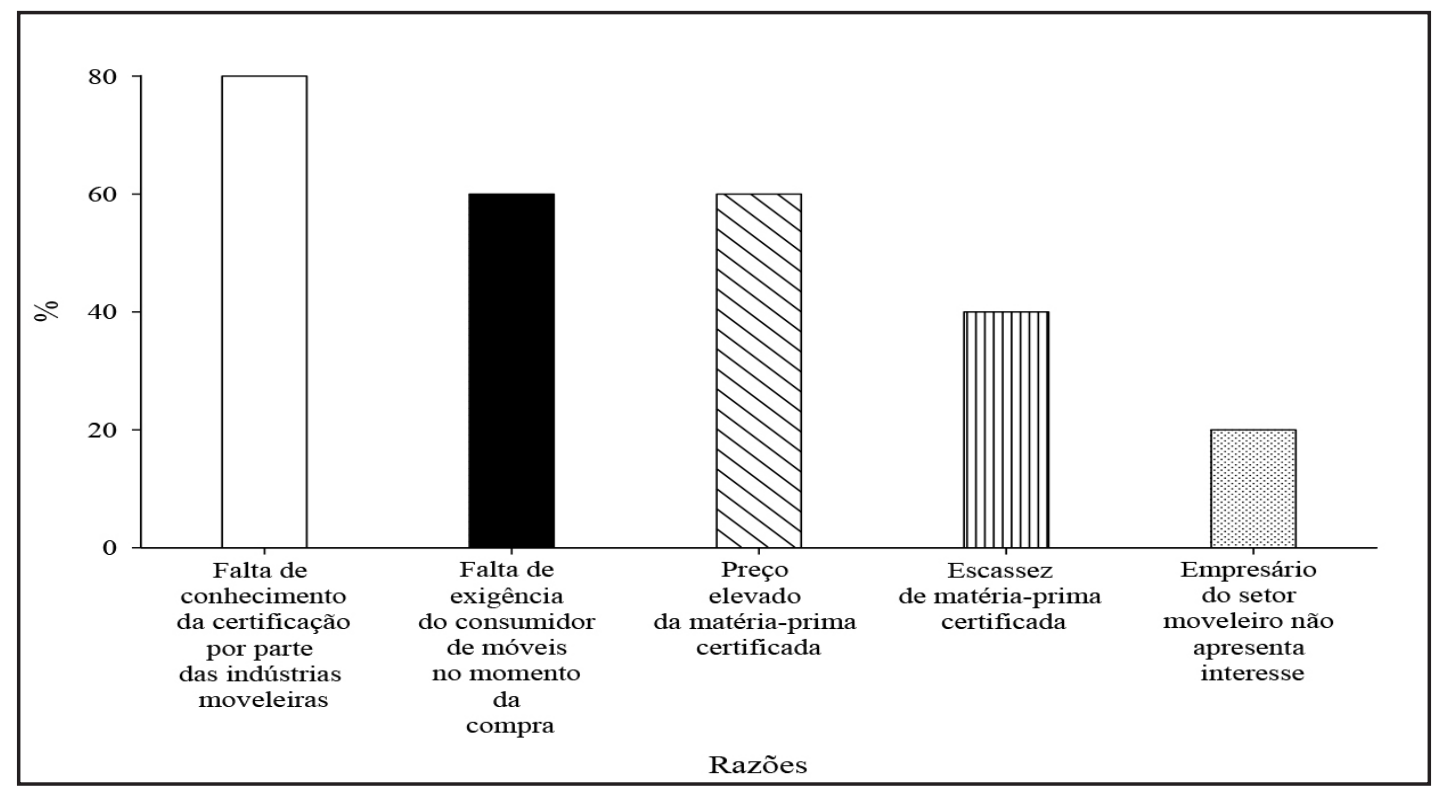

Fonte: Autores (2016)

Das empresas investigadas, $60 \%$ revelaram que a falta de exigência do consumidor de móveis pelo certificado no momento da compra, contribui para o pequeno número de empresas do setor moveleiro com certificado de cadeia de custódia (FSC/CoC) (Figura 4). Esse fator pode desestimular o investimento, se não existe a demanda, dificilmente a empresa colocará seu capital em tal empreendimento. O consumidor brasileiro, em sua maioria, não conhece a certificação florestal e não reconhece o selo nos produtos (ALVES; JACOVINE; EINLOFT, 2009 
a). Apenas $20 \%$ das empresas moveleiras da região metropolitana do Rio de Janeiro consideraram a escassez de matéria-prima certificada um fator relevante para o baixo número de empresas moveleiras certificadas (Figura 4). Para a maioria das empresas moveleiras que utiliza os painéis como matéria-prima, a certificação florestal é favorecida pelo fato de que grande parte de seus principais fornecedores já são certificados pelo FSC, o que garante um suprimento considerável de insumo (ALVES et al., 2009b). A maioria (75\% das empresas) afirmou que aumentar a divulgação da certificação florestal entre os consumidores finais é a principal ferramenta para impulsionar o mercado de produtos certificados nos próximos anos (Figura 5).

\section{Figura 5 - Fatores que as empresas moveleiras consideram fundamentais para alavancar o mercado de produtos certificados nos próximos anos}

Figure 5 - Factors that furniture companies consider fundamental to leverage the certified products market in the coming years

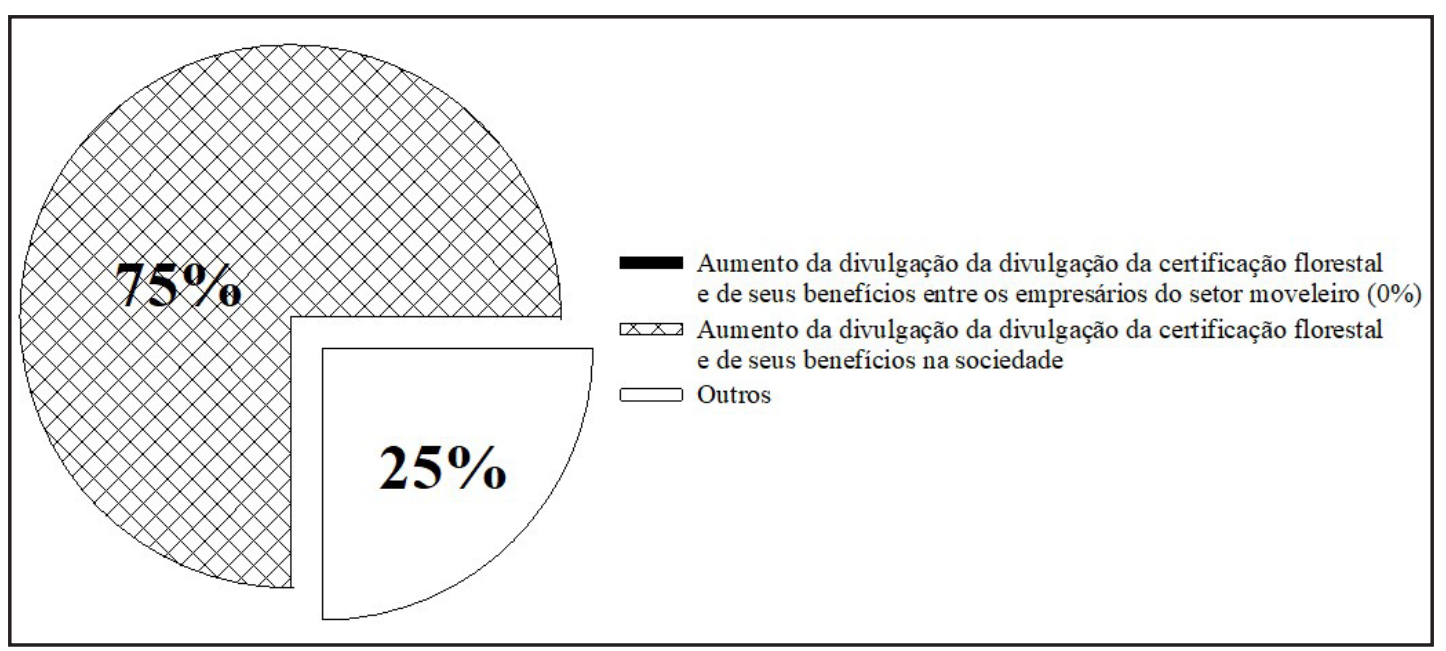

Fonte: Autores (2016)

O número de empresas do setor moveleiro com certificado de cadeia de custódia, somente será perceptivo, quando a certificação for vista como um sinalizador ao consumidor em relação aos as pectos ambientais inerentes ao produto (ALVES, 2010). Soares et al. (2011) relatam que uma maior divulgação da certificação florestal pelo governo, a exigência da certificação em compras governamentais e a criação de um padrão de certificação para os pequenos e médios produtores, poderão impulsionar a certificação florestal no Brasil.

A maioria das empresas moveleiras da região metropolitana do Rio de Janeiro $(80 \%)$ acredita que em um futuro próximo que, os clientes estarão mais criteriosos com relação aos produtos que consomem, exigindo assim, um certificado comprobatório dos mesmos, como, por exemplo, o de cadeia de Custódia FSC/CoC. A principal vantagem que a maioria das empresas moveleiras da região metropolitana do Rio de Janeiro supõe existir com a aquisição do certificado florestal (FSC/CoC) é a melhoria da imagem institucional ( $80 \%$ das empresas) (Figura 6). 


\section{Figura 6 - Vantagens que as empresas moveleiras supõem existir com a aquisição do certificado florestal}

Figure 6 - Advantages that furniture companies supposed to exist with the acquisition of forest certification

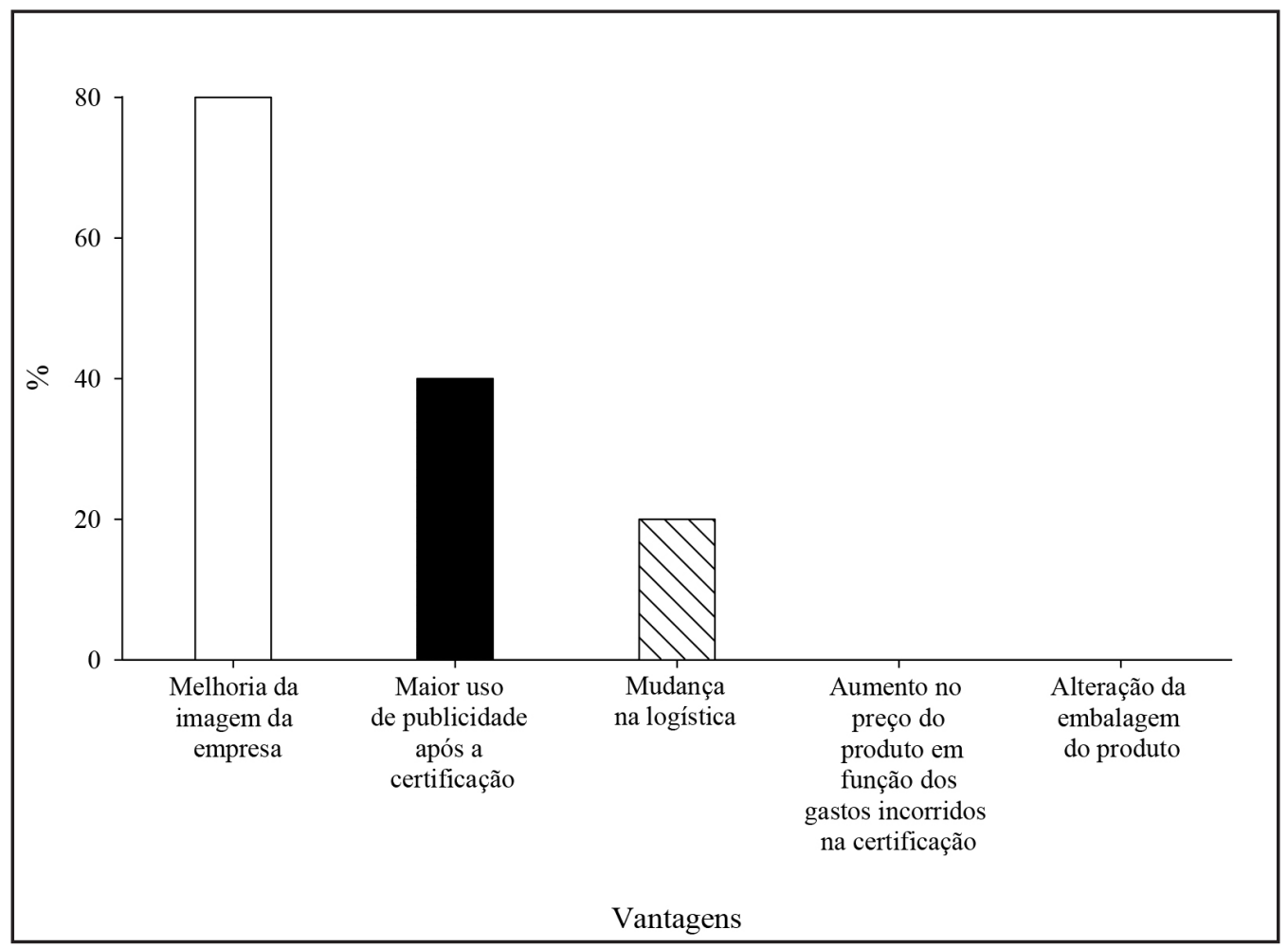

Fonte: Autores (2016)

Vários são os benefícios da certificação FSC para os empreendedores, entre os principais, destacam-se: acesso a novos mercados ou manutenção dos atuais; acesso facilitado a financiamentos; contribuições socioambientais e melhoria da imagem da empresa (ALMEIDA, 2012; BAPTISTEL; CANCI; LANGER, 2011). A indústria moveleira que não possui o certificado de cadeia de custódia não somente deixa de promover todo um sistema que se pauta por princípios ambientais e sociais, mas, sobretudo, deixa de associar sua imagem institucional a selos reconhecidos internacionalmente (FSC); e ainda, não aproveita as oportunidades de mercado, especialmente no exterior (ALVES et al., 2009b).

Alves et al. (2007) consideram a certificação florestal um instrumento de diferenciação diante da concorrência, ou seja, significa distinguir-se dos demais através de uma representação que reforce os compromissos ambientais e sociais da empresa perante a sociedade. A certificação não significa, necessariamente, maiores custos ou redução de lucros, mas uma estratégia que pode ser utilizada para aproveitar todas as oportunidades, aumentando e mantendo a eficiência das organizações (ALVES; JACOVINE; EINLOFT, 2009a). A certificação florestal torna-se uma importante ferramenta gerencial para as empresas. Para algumas instituições a adoção dos padrões pode oferecer uma oportunidade de melhorar continuamente suas atividades, a confiabilidade de seus produtos ou serviços e a qualidade das relações com os clientes, empregada (JACOVINE et al., 2006a). Com a aquisição do selo verde existe a possibilidade de novos negócios, novos tipos de produtos e uma melhor margem de lucros. Outro aspecto é o da imagem de "empresa verde". Esta imagem, que a cada dia se solidifica no Brasil e no mundo, é a de organizações vistas como empresas honestas que operam de forma correta, respeitam as leis trabalhistas, as leis de 
segurança do trabalho, mas principalmente, preocupam-se e agem de forma a proteger o meio ambiente (PUCCI, 2012).

\section{Conclusões}

A maioria das indústrias moveleiras com parque fabril da região metropolitana do Rio de Janeiro consegue cumprir os requisitos exigidos pela norma de certificação FSC/CoC. Os requisitos "disposição de licenças e outros documentos legais", "disponibilidade de um responsável pelo processo de certificação de cadeia de custódia” e "capacitação de seus funcionários” foram os que influenciaram a maioria das empresas moveleiras a não estar apta à obtenção do certificado de cadeia de custódia.

A maioria das indústrias moveleiras encontra-se preparada para a obtenção do certificado de cadeia de custódia. O requisito "gestão de recursos" não foi cumprido por nenhuma das empresas moveleiras com parque fabril da região metropolitana do Rio de Janeiro.

\section{Agradecimentos}

Aos Sindicatos da região: SIM-Rio (Sindicato das Indústrias de Móveis de Madeira do Município do Rio de Janeiro) e SINCOCIMO (Sindicato das Indústrias de Construção Civil e do Mobiliário da Baixada Fluminense), ao SEBRAE e à FIRJAN.

\section{Referências}

ALMEIDA, R. C. Certificação Florestal: uma análise dos protocolos do FSC para emissão do selo verde e das normas estatais para o licenciamento florestal no estado do Pará. 2012. 138 f. Dissertação (Mestrado em Desenvolvimento Sustentável do Trópico Úmido) - Universidade Federal do Pará. Belém, 2012.

ALVES, R. R. Marketing, estratégica competitiva e viabilidade econômica para produtos com certificação de cadeia de custódia na indústria moveleira. 2010. 367 f. Tese (Doutorado em Ciências Florestais) - Universidade Federal de Viçosa. Viçosa, 2010.

ALVES, R.R. et al. Certificação florestal e o mercado moveleiro nacional. Árvore, Viçosa, v.33, p.583-589, 2009a.

ALVES, R.R. et al. Certificação Florestal e o consumidor final: um estudo no polo moveleiro de Ubá - MG. Floresta e Ambiente, Seropédica, v.16, p. 40-48, 2009 b.

ALVES, R.R.; JACOVINE, L.A.G.; EINLOFT, R. Cadeia de custódia amplia selo verde. Revista da Madeira, Curitiba, n. 121, 2009a.

ALVES, R.R.; JACOVINE, L.A.G.; EINLOFT, R. Indústria moveleira impulsiona certificação florestal. Revista da Madeira, Curitiba, n.120, 2009 b.

ALVES, R.R. et al. Certificação Florestal na visão gerencial e estratégica do polo moveleiro de Ubá, MG. Cerne, Lavras, v. 13, p. 117-122, 2007.

ARAUJO, M. et al. Why Brazilian companies are certifying their forests? Forest Policy and Economics, Elsevier, v. 11, p. 579-585, 2009.

BAPTISTEL, A.L.; CANCI, R.C.; LANGER, M. Análise do processo de certificação florestal FSC em empresas florestais na região de Lages/SC. Unoesc \& Ciência, Joaçaba, v. 2, n. 2, p. 111-118, 2011.

DA LUZ, M.C.P.N. FSC e Cerflor: trocando em miúdos. Revista Tecnológica Gráfica, São Paulo, n. $74,2010$. 
FARIA, A.B.C. Revisando o processo de certificação florestal. Revista Ambiência, Guarapuava, v.5, n.1, p.145-153, 2009.

FOREST COUNCIL STEWARDSHIP BRASIL. FSC. Guias de compras de produtos certificados FSC. Páginas verdes, Brasília. 2013. Disponível em: br.fsc.org/download.guia-pginas-verdes.68.htm. Acesso em: 20 set. 2019.

FOREST COUNCIL STEWARDSHIP. FSC. Tipos de Certificados FSC. FSC online, Brasília. 2019. Disponível em: http://br.fsc.org/tipos-de-certificados.204.htm. Acesso em: 20 set. 2019.

GUSMÃO, C.; JUNIOR, W.; BASSO, V.M. Certificação de Cadeia de Custódia para produtos florestais. Disponível em: http://www.florestascertificadas.org.br/noticias/certificacao-decadeia-de-custodia-para-produtos-florestais. 2014. Acesso em 14 ago. 2015.

JACOVINE, L.A.G. et al. Processo de implementação da certificação florestal nas empresas moveleiras nacionais. Árvore, Viçosa, v. 30, n.6, p. 961-968, 2006 .

JACOVINE, L.A.G. et al. Certificação florestal na visão gerencial e estratégica da indústria moveleira nacional. Semina: Ciências Agrarias, Londrina, v. 27, n. 3, p. 367-378, 2006b.

JÚNIOR, I.M. et al. Gestão da qualidade. Rio de Janeiro: FGV, 2008. 204p.

LUZ, R.S.O.; LIGUORI, V.C.S. Orientações sobre Sistema de Gestão da Qualidade. Campinas: Centro de Tecnologia da Informação Renato Archer, 2012. 22p.

MARCOVITCH, J. Certificação e sustentabilidade ambiental: uma análise crítica. 2012. 148 f. Monografia (Graduação em Administração) - Universidade de São Paulo. São Paulo, 2012.

MINGOTI, S.A. Análise de dados através de métodos de estatística. Minas Gerais: UFMG, 2013. 297p.

PINTO, L.F.G.; PRADA, L.S. Fundamentos da certificação. In: ALVES, F.; FERRAZ, J.M.G.; PINTO, L.F.G.; SZMRECSÁNYI, T. Certificação socioambiental para a agricultura: desafios para o setor sucroalcooleiro. Piracicaba: Imaflora, 2008. p. 20-37.

PINTO, S.H.B.; GRANJA, C.P. Análise crítica da certificação florestal Brasileira- Cerflor e a Forest Stewardship Council- FSC: um estudo de múltiplos casos. In: XXXII ENCONTRO NACIONAL DE ENGENHARIA PRODUÇÃO, 2013, Salvador. Anais... Salvador, ENEGEP, 2013. p. 22357.

PUCCI, M. Integração do sistema de cadeia de custódia (FSC) em um sistema de gestão da qualidade (ISO 9001) de uma gráfica de embalagens. 2012. 180 f. Monografia (Tecnologia em Planejamento e Produção de Mídia Impressa) - Faculdade SENAI de Tecnologia Gráfica. São Paulo, 2012.

SOARES, M.F. Análise de integração em sistemas de gestão baseados nas Normas ISO 9001 , ISO 14001 e OHSAS 18001 em empresas de construção civil. 2013. 149 f. Dissertação (Mestrado em Engenharia Civil) - Universidade Federal do Ceará. Fortaleza, 2013.

SOARES, N.S. et al. Dificuldades para a certificação florestal no Brasil. CIFlorestas. Texto Técnico. Viçosa, 2011. 4p. 